\title{
Radical mutations reveal TATA-box binding protein surfaces required for activated transcription in vivo
}

\author{
Gene O. Bryant, ${ }^{1}$ Lisa S. Martel, ${ }^{1}$ Stephen K. Burley, ${ }^{2}$ and Arnold J. Berk ${ }^{1,3}$ \\ ${ }^{1}$ Department of Microbiology and Molecular Genetics, Molecular Biology Institute, University of California, Los Angeles, \\ California 90095-1570 USA; ${ }^{2}$ Laboratories of Molecular Biophysics, The Rockefeller University, Howard Hughes Medical \\ Institute, New York, New York 10021-6399 USA
}

\begin{abstract}
Regions on the surface of human TATA-box binding protein (TBP) required for activated transcription in vivo were defined by construction of a library of 89 surface residue mutants with radical substitutions that were assayed for their ability to support activated transcription in vivo, basal transcription in vitro, and TFIIA and TFIIB binding in vitro. Four epitopes were identified in which substitutions in two to four neighboring surface residues greatly inhibited activated transcription in vivo. One epitope in which substitutions inhibited both basal and activated transcription (E284, L287) is the interface between TBP and TFIIB. Another (A184, N189, E191, R205) is the recently determined interface between TBP and TFIIA. Mutations in residues in this TFIIA interface greatly inhibit activated, but not basal transcription, demonstrating a requirement for the TFIIA-TBP interaction for activated transcription in vivo in mammalian cells. The remaining two activation epitopes (TBP helix 2 residues R231, R235, R239, plus F250; and G175, C176, P247) are probably interfaces with other proteins required for activated transcription. The library of mutants responded virtually identically to two different types of activators, GL4-E1A and GAL4-VP16, indicating that transcriptional activation by different classes of activators requires common interactions with TBP.
\end{abstract}

[Key Words: TBP; TFIID; transcription; activation; TFIIA]

Received June 24 1996; revised version accepted August 9, 1996.

The TATA-box binding protein (TBP) is an essential transcription factor for each of the three eukaryotic nuclear RNA polymerases (Hernandez 1993; Burley and Roeder 1996). In mammalian and Drosophila systems for transcription of protein-coding genes by RNA polymerase II (Pol II), TBP is associated with $\sim 12$ (human) or 9 (Drosophila) additional polypeptides called TBP-associated factors (TAFs) in the general transcription factor TFIID (Dynlacht et al. 1991; Goodrich and Tjian 1994; Burley and Roeder 1996). On promoters with a TATA box ( $~ 80 \%$ of protein-coding genes; Bucher 1990), TFIID initiates assembly of an approximately ribosome-size preinitiation complex $\left(\sim 4 \times 10^{3} \mathrm{kD}\right)$ by binding to TATA-box DNA (Davison et al. 1983; Burley and Roeder 1996). The TBP polypeptide binds to general transcription factors TFIIA (Geiger et al. 1996; Tan et al. 1996) and TFIIB (Nikolov et al. 1995) and can participate in an in vitro basal transcription reaction along with TFIIB, TFIIF, Pol II, TFIIE, and TFIIH (Burley and Roeder 1996). Activation of transcription in vitro, however, requires TFIID TAFs (Dynlacht et al. 1991; Goodrich and Tjian 1994; Burley and Roeder 1996) and other coactivators

${ }^{3}$ Corresponding author.
(Ge and Roeder 1994; Kaiser et al. 1995; Luo and Roeder 1995; Shykind et al. 1995), or, in Saccharomyces cerevisiae, polypeptides associated with a Pol II holoenzyme complex (Kim et al. 1994; Koleske and Young 1994).

In vitro TBP binds multiple polypeptides in addition to TFIIA and TFIIB. Among these are activation domains (Stringer et al. 1990; Horikoshi et al. 1991; Lee et al. 1991), the Pol II large subunit carboxy-terminal repeat domain (CTD) (Usheva et al. 1992), repression domains (Um et al. 1995), transcriptional inhibitors (Yeung et al. 1994; Kim et al. 1995), and TFIIF (Tang et al. 1996). To test the significance of these interactions observed in vitro for activated transcription in vivo, we constructed a library of human TBP mutants, each with a single amino acid residue substitution within the 180-residue essential carboxy-terminal core domain at a site where the side chain of the wild-type residue is exposed to solvent in the crystal structure of the TBP-TATA box DNA complex (Kim et al. 1993; 1995). Only the TBP core domain was analyzed, as the amino-terminal domain of human TBP is not required for activated transcription in vitro (Q. Zhou et al. 1993) or in vivo (Keveaney et al. 1993; Tansey et al. 1994). We expected that substitutions in a subset of surface residues would weaken or block TBP binding to proteins with which it must normally interact 
during regulated transcription. By correlating the effects of mutations on TBP binding in vitro with effects on transcription in vivo, we hoped to distinguish which interactions observed in vitro make important contributions to transcription in vivo.

Earlier studies of TBP mutants have already revealed a great deal about how the protein functions in Pol II transcription. Residues E284, E286, and L287 at the tip of the second stirrup of the saddle-shaped molecule (Kim and Burley 1994) have been shown to be critical to TFIIB binding and in vitro transcription (Kim et al. 1994, 1995; Tang et al. 1996). An analysis of human TBP mutants with multiple simultaneous substitutions in surface residues suggested that the TBP interaction with $\mathrm{TAF}_{\mathrm{II}} 250$ is required for activated transcription in vivo (Tansey et al. 1996). S. cerevisiae TBP has been subjected to extensive genetic analysis. TBP mutants specifically defective in supporting activated transcription by Pol II have been isolated and fall into several classes. One class has amino acid substitutions in the DNA-binding surface of TBP that reduce the protein's affinity for TATA boxes (Arndt et al. 1995; Lee and Struhl 1995). One mutant specifically defective in supporting activated transcription is defective in binding to TFIIA (Stargell and Struhl 1995), and several have been described recently that have substitutions on the upper surface of the TBP molecule (Stargell and Struhl 1996). Further genetic analyses support the significance of the TBP-TFIIA interaction for activated transcription in vivo (Stargell and Struhl 1995) and demonstrate that increased binding of TBP to promoter DNA is sufficient to activate transcription /Chatteriee and Struhl 1995; Klages and Strubin 1995; Xiao et al. 1995). These and other studies (Klein and Struhl 1994; Stargell and Struhl 1996) support the model that activators stimulate transcription by increasing the binding of TBP to nearby TATA boxes.

\section{Results}

In most cases, we introduced radical amino acid substitutions onto the surface of TBP to increase the likelihood that a single mutation would disrupt TBP's interaction with another protein in vitro and produce a clear phenotype in vivo. Lysine and arginine residues were substituted with glutamic acid, and aspartic and glutamic acid residues were substituted with arginine to change possible electrostatic attractions to repulsions. In most other cases, residues were substituted with glutamic acid or arginine to introduce a bulky, charged side chain that might sterically block interactions with neighboring regions of the TBP surface. Because we were interested in identifying sites of protein-protein interaction, we did not mutate TBP residues that interact directly with DNA, except in a few cases. Eighty-nine single-residue substitution mutants (Table 1) were constructed and tested for their abilities to support activated transcription in vivo in a transient transfection assay in COS cells, to interact with TFIIA and TFIIB in gel mobility shift assays, and to support basal in vitro transcription.

Mutant TBPs expressed in and purified from Esche- richia coli (Fig. 1A) were assayed for DNA binding alone and in the presence of recombinant TFIIA and/or TFIIB by gel mobility shift assay (Buratowski et al. 1989; Table 1; representative results shown in Fig. 1B). These results will be discussed below together with results on in vivo function of these mutants. But in analyzing the in vivo data, it is essential to eliminate the class of mutations that inhibit TBP DNA-binding activity. Considering the radical nature of the substitutions introduced, we anticipated that some of the mutations might significantly distort TBP's conformation or even interfere with protein folding. Such mutants were recognized by their inability to bind DNA, because the structure of the TBP DNA-binding surface, that is, the bottom of the saddleshaped molecule (see Fig. 5, below), depends on the overall conformation of the 180 residue carboxy-terminal core domain. Fourteen mutants failed to form DNA-protein complexes with TATA-box DNA in the gel mobility shift assay in the presence of either TFIIA or TFIIB (Table 1; e.g., Fig. 1B, A190E). These mutants may be improperly folded, and any reduction in function they may exhibit in vivo (see below) may be explained by their inability to bind TATA-box DNA.

To assay the influence of these surface residue substitutions on activated transcription in vivo, surface mutations were constructed on the background of the $\mathrm{m} 3$ triple mutation (Strubin and Struhl 1992). The three m3 mutations in the DNA-binding surface of TBP relax its binding specificity, allowing it, unlike wild-type TBP, to bind to a TGTAAA sequence with an affinity similar to that of wild-type TBP for a TATAAA box. This experimental method allows one to assay the influence of additional mutations in TBP on its ability to support Pol II transcription in vivo by assaying expression from a reporter gene with a TGTAAA box (Strubin and Struhl 1992).

We called the human TBP mutant with the three $\mathrm{m} 3$ mutations in the DNA-binding surface, but otherwise wild-type surface residues, wt $\mathrm{hm} 3$. Wt $\mathrm{hm} 3$ and all of the TBP mutants were epitope-tagged at the amino terminus so that expression levels could be assayed by Western blotting. We used two different TGTAAA-box reporter constructs with upstream GAL4-binding sites to test the generality of the mutant TBP phenotypes on different promoters. One used the promoter region from c-fos (Tansey et al. 1994), and the other, the $\beta$-retinoic acid receptor gene promoter region (Keaveney et al. 1993; Fig. 2).

To determine whether different surfaces of TBP are required for activation by different classes of activators, we analyzed activation by two different activation domains, one in GAL4-VP16 (Sadowski et al. 1988) and the other in GAL4-E1A conserved region 3 (CR3) (Martin et al. 1990). These two activation domains probably function by distinct mechanisms because VP16 is a prototype acidic activation domain (Cress and Triezenberg 1991; see also Leuther et al. 1993), whereas E1A CR3 is not an acidic activator (Martin et al. 1990; Webster and Ricciardi 1991). Also, GAL4-VP16 is a potent activator in $S$. cerevisiae (Sadowski et al. 1988), whereas GAL4-E1A is 


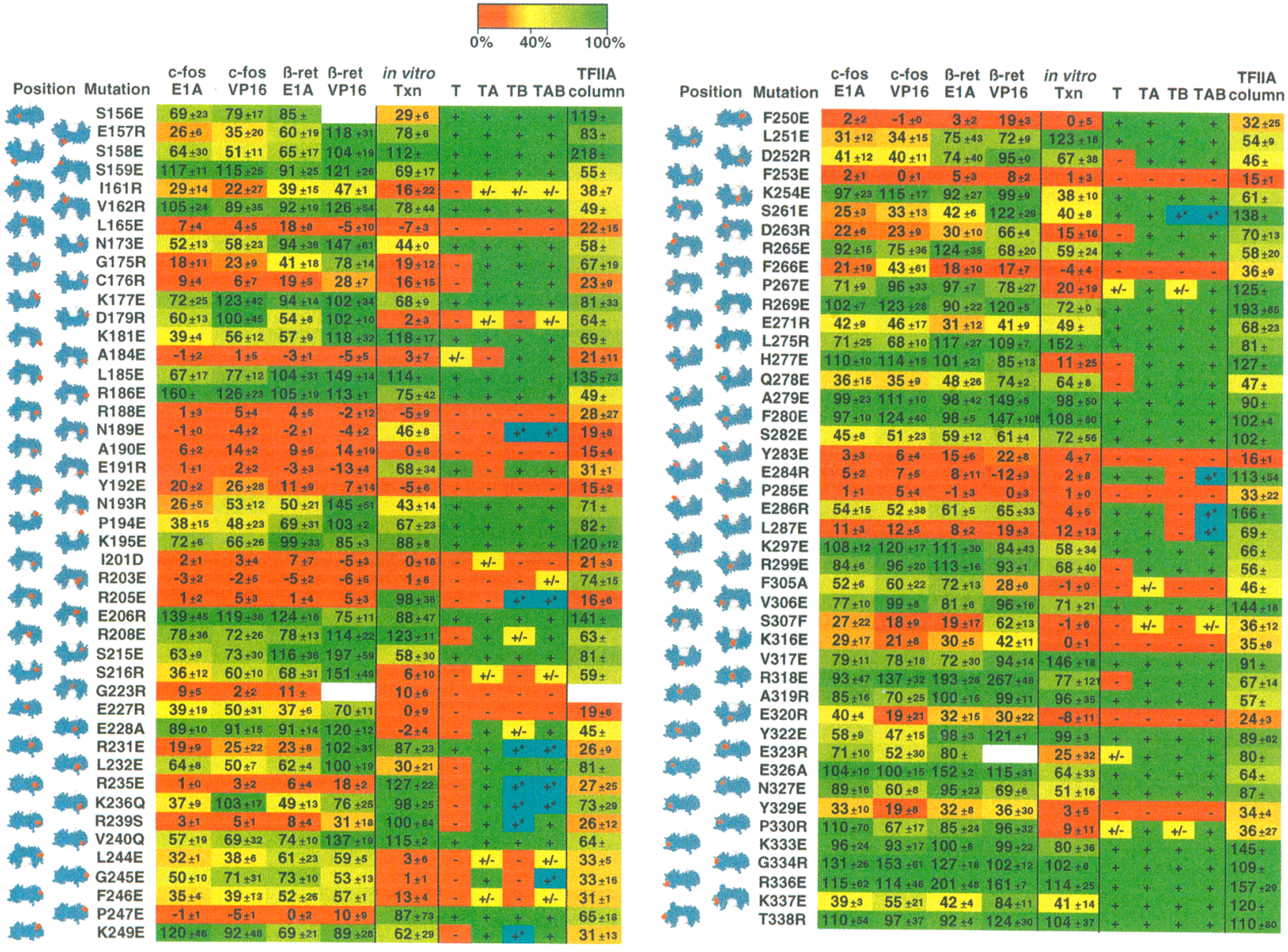

Diagrams at the left indicate the position of the mutation on the surface of TBP (highlighted in red and enlarged) with the TBP molecule shown in one of the three positions presented in Fig. 5. The first four columns show results of in vivo function assays. Luciferase activity is shown as a percentage of that observed with wt hm3 for activation by Gal4-E1A (E1A) and Gal4-VP16 (VP16) from TGTAAA-box reporter genes using the $\mathrm{c}$-fos and $\beta$-retinoic acid receptor gene ( $\beta$-ret) promoter regions. Values are means of three independent transfection assays \pm S.D. "in vitro Txn" shows activity in a basal transcription reaction (see Materials and Methods) as a percentage of the transcription observed with wt hm3. Values shown \pm S.D. are means and S.D. of $2-3$ assays. Values without a S.D. are from a single assay. Columns 6-9 summarize gel shift assay results for reactions with mutant TBP alone (T), plus TFIIA (TA), plus TFIIB (TB), plus TFIIA and TFIIB (TAB). $(+\mid$ Addition of protein produced a new complex $;(+)$ addition of protein produced a new complex but with a different mobility from wt hm3; (-) no new complex observed compared with mutant TBP alone. The right column shows the percent binding to a Gst-TFIIA $\alpha \beta+\gamma$ column relative to $100 \%$ for wt hm3. Values showing S.D. are averages of $2-4$ determinations.

an extremely weak activator in this organism (T.G. Boyer and A.J. Berk, unpubl.).

Of the 75 TBP mutants that bind TATA-box DNA together with either TFIIA or TFIIB, 13 were severely reduced $(<20 \%$ of the activity of wt $\mathrm{hm} 3)$ in their ability to support transcriptional activation by GAL4-E1A / Table 1, Fig. 3). Similar results were observed when each mutant was tested for its ability to support activation by GAL14-VP16 (Fig. 3). Results with both activators were similar on both the $c$-fos and $\beta$-retinoic acid receptor TGTAAA-box reporter genes (Table 1). Because similar results were observed for each TBP mutant on two different promoter regions and in response to two different activators, these results probably reflect general aspects of TBP function in Pol II transcription from promoters with a TATA box. We were not able to detect significant expression from these reporter genes without cotransfecting an expression vector for a GAL4 DNA-binding domain fused to an activation domain. Consequently, in vivo basal activity (if such a thing occurs in mammalian cells) could not be assayed.

To determine whether the in vivo activity of these mutants was affected by their expression levels, mutant TBPs were analyzed by Western blotting of whole-cell extracts from transfected cells with a monoclonal antibody specific for the amino-terminal epitope tag (repre- 


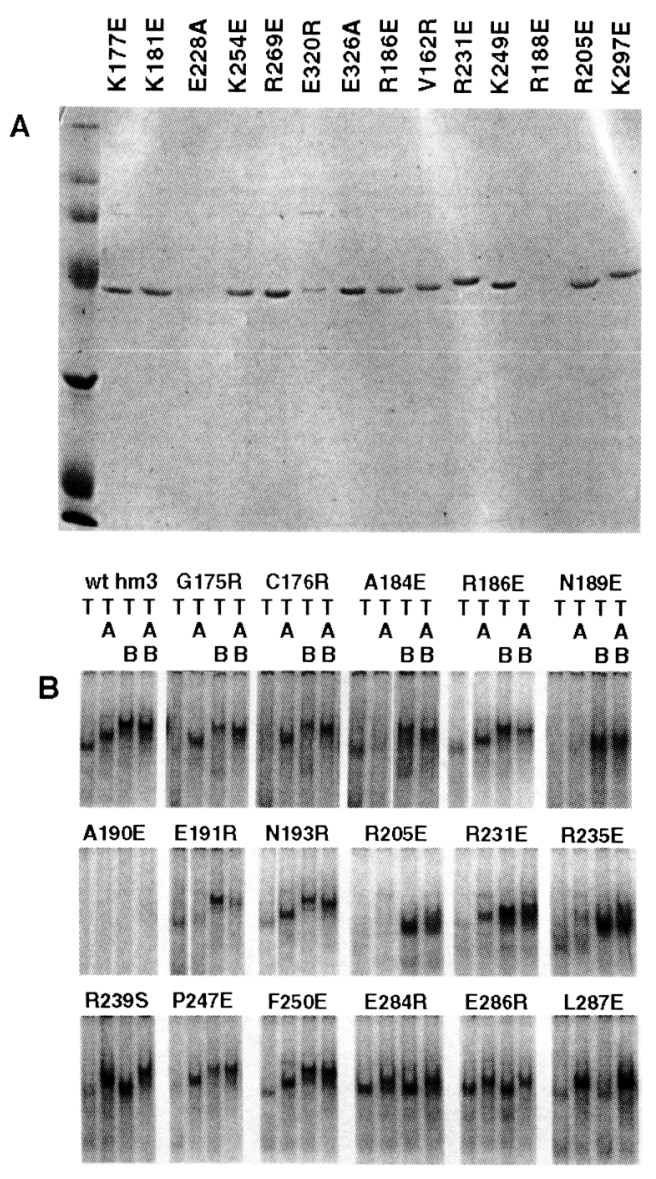

Figure 1. Gel mobility-shift assays. (A) Representative Coomassie blue-stained SDS-PAGE gel of purified mutant hTBPs expressed in E. coli. Mutants E228A and R188E were expressed at lower levels than the other mutants. $(B)$ Representative gel mobility-shift assays. Letters above a lane indicate the proteins added to the binding reaction: $(\mathrm{T})$ mutant $\mathrm{TBP} ;(\mathrm{A})$ TFIIA; (B) TFIIB.

sentative data shown in Fig. 4). Expression levels varied, but did not correlate with activity in the transfection assay. For example, mutants L185E and F280E had in vivo activities similar to that of $\mathrm{wt} \mathrm{hm} 3$, yet were expressed at lower levels. This indicates that the high level of altered-binding-site TBP expressed from these replicating vectors saturates the transient transfection assay. Several mutants that were expressed at levels higher than wt hm3 had activities similar to wt hm3 (E228A, S215E, P267E, and V317E), indicating that squelching does not appear to be an important factor at these levels of expression in this assay.

In four successive transfection/Western blot experiments like that shown in Figure 4, for the mutants with $<20 \%$ wt hm3 activity, N189E, R205E, R231E, R235E, P247E, E284R, and L287E were expressed at 50-100\% the level of wt hm3. Mutants C176R, E191R, and R239S were expressed at $25-50 \%$ of wt hm 3 concentration. $\mathrm{Mu}$ tants G175R, A184E, and F250E, however, were consistently expressed at about $25 \%$ or less the level of wt $\mathrm{hm} 3$. Consequently, the low in vivo activities of $\mathrm{mu}$ tants N189E, E191R, R205E, R231E, R235E, R239S, E284R, and L287E result from defects in the function of these mutant TBPs and not from low expression levels. On the other hand, the low expression levels of mutants G175R, A184E, and F250E may have contributed to their low in vivo function. Also, the high expression level of some mutants in the transfection assay might mask the effects of mutations by driving weakened associations with other transcription factors through mass action.

The regions on TBP's surface in which mutations significantly blocked in vivo function fall into four epitopes of two to four neighboring residues (Fig. 5): the tip of the second repeat stirrup (E284R, L287E), the upstream surface of the first repeat (A184E, N189E, E191R, R205E), the top of the first repeat $(\mathrm{H} 2$ helix residues R231E, $\mathrm{R} 235 \mathrm{E}, \mathrm{R} 239 \mathrm{~S}$; and F250E), and a region on the downstream surface of the first repeat, near the top (G175R, $\mathrm{C} 176 \mathrm{R}, \mathrm{P} 247 \mathrm{E})$. The phenotypes produced by substitutions in two of these regions can be explained by the disruption of presently understood TBP interactions with two general transcription factors.

\section{Reporter Plasmids:}

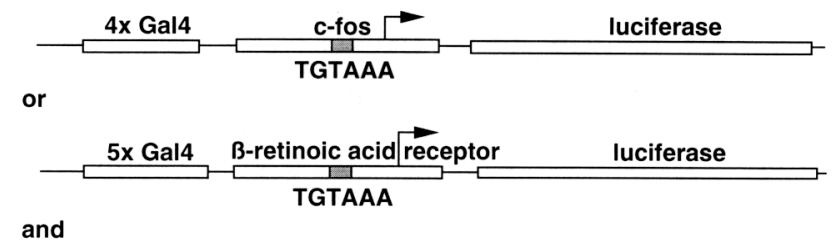

Expression Plasmids:

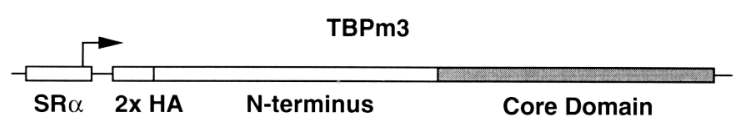

and

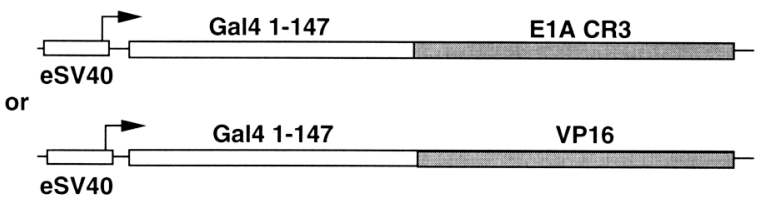

and

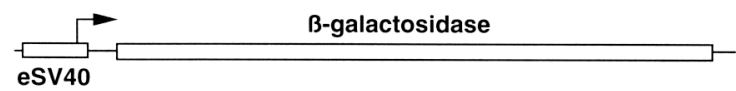

Figure 2. Plasmids used in the in vivo function assays. The reporter plasmid was derived either from the c-fos promoter region (Tansey et al. 1994) or the $\beta$-retinoic acid receptor gene promoter region (Keaveney et al. 1993). Mutant TBPs with an amino-terminal epitope-tag were expressed from an $\mathrm{SR} \alpha$ promoter/enhancer. GAL4 DNA-binding domain fusions to E1A conserved region 3 or the VP16 activation domain were expressed from the early SV40 promoter/enhancer, as was $\beta$-galactosidase as an internal control for transfection efficiency. 

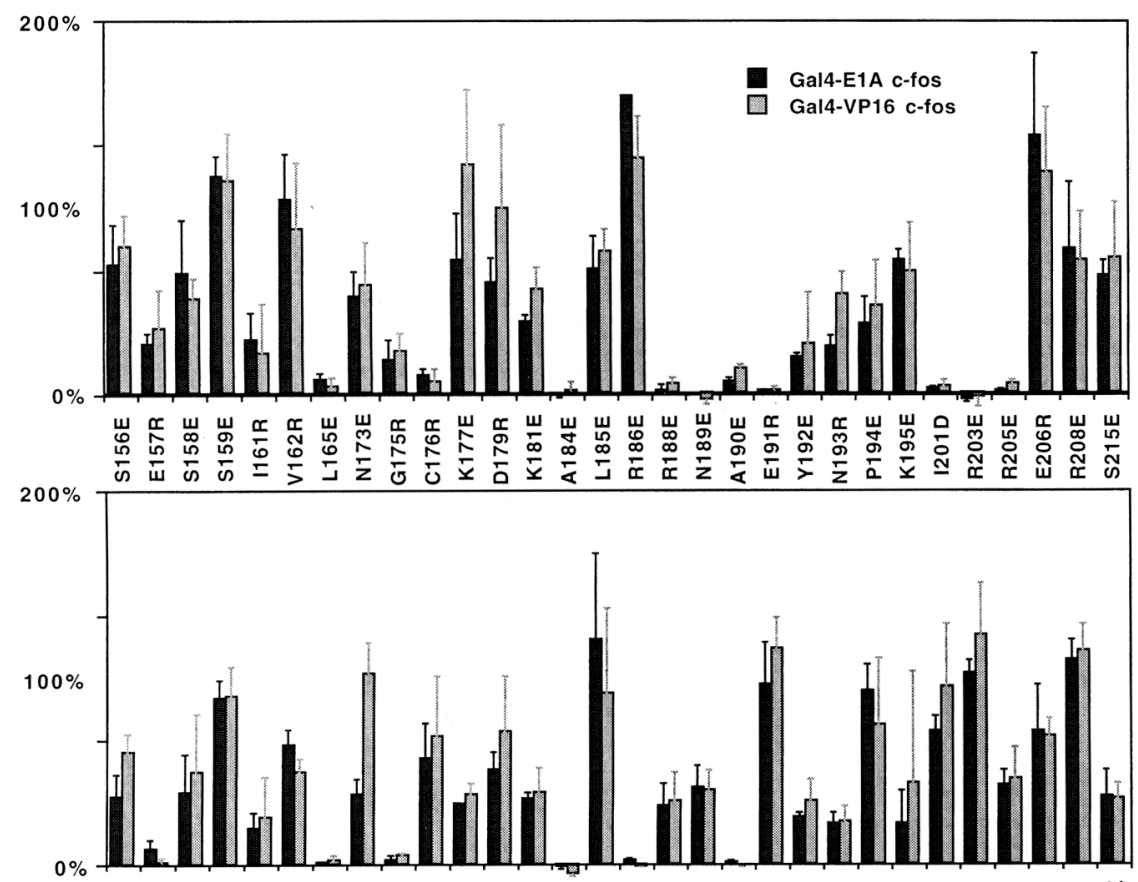
๔

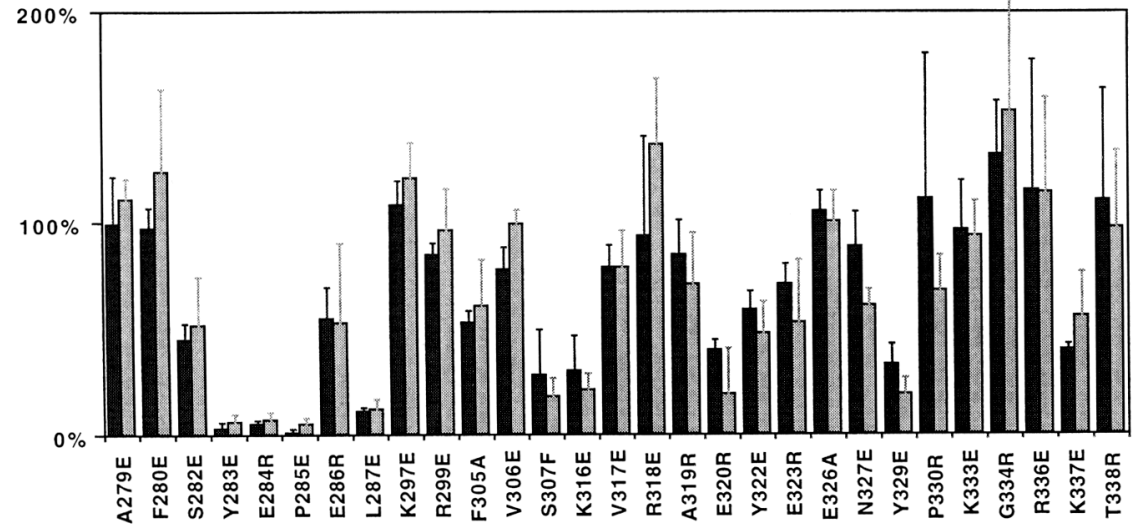

Figure 3. In vivo function of TBP mutants. Activity is shown as a percentage of luciferase activity observed with wt hm3. Activities in transfections with GAL4-ElA and GAL4-VP16 are shown by solid and shaded bars, respectively.
Mutations at E284, E286, and L287 inhibited TFIIB binding to TBP-TATA box DNA in an earlier alanine scanning analysis of the human TBP surface (Tang et al. 1996). Our substitutions in the same residues also inhibited TFIIB binding (Table 1; Fig. 1B). These three residues are deeply buried in the TFIIB core domain in the TFIIBTBP-TATA box DNA crystal structure, and each of these three residues directly contacts TFIIB residues ( $\mathrm{Ni}$ kolov et al. 1995; see Fig. 6). Consequently, the finding that our substitutions E284R, E286R, and L287E inhibit the TFIIB-TBP interaction is readily explained. The crystal structure of the complex also shows contacts between TFIIB and TBP residues corresponding to human residues Y283 and P285. Our mutations constructed at these positions yielded mutant TBPs that do not bind DNA (Table 1). Consequently, their impact on TFIIB binding could not be assessed in the gel mobility shift assay.
These three mutants (E284R, E286R, and L287E) were also defective for basal in vitro transcription (Table 1; Fig. 7), consistent with biochemical studies showing that TFIIB is required for both basal and activated in vitro transcription (Buratowski and Zhou 1993; Ha et al. 1993; Hisatake et al. 1993). Consequently, the failure of mutants E284R and L287E to support activated transcription in vivo is likely caused by a block in TFIIB binding. Surprisingly, mutant E286R was reduced by only a factor of two in the in vivo assay (Table 1; Fig. 3), even though its ability to form a gel mobility shift complex with TBP-DNA was extremely reduced, even at high TFIIB concentration (Fig. 8B), and even though it had no in vitro basal transcription activity (Fig. 7).

Substitutions in a second epitope on the upstream surface of the first TBP repeat (A184E, N189E, E191R, R205E; Fig. 5) inhibited formation of the TFIIA-TBPDNA (TA) complex in the gel mobility shift assay (Table 


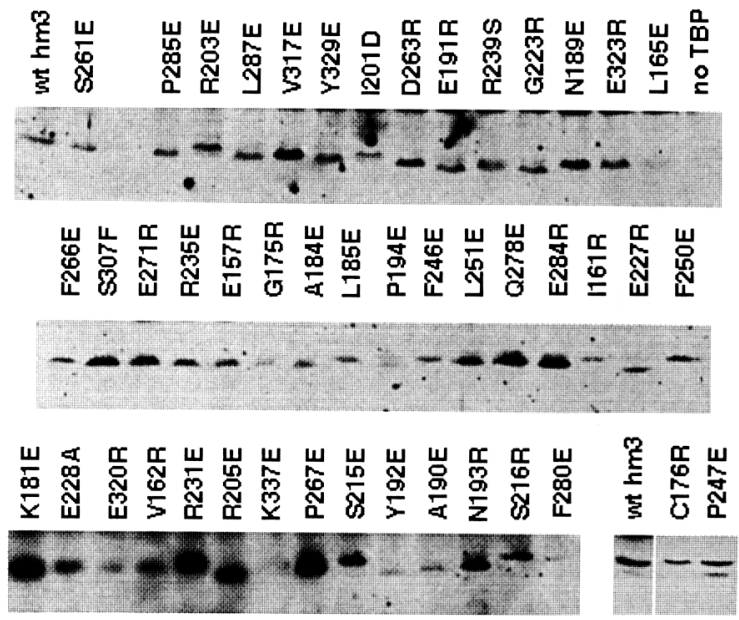

Figure 4. In vivo expression of mutant TBPs in transfected cells. Mutants with $<50 \%$ of the activity of wt hm 3 and eight mutants with $>50 \%$ of this in vivo activity were analyzed. COS cells were transfected with the standard amount of mutant TBP expression vector used in the in vivo assays of Table 1 and Figure 3. TBPs with two copies of the amino-terminal epitope were expressed. Total cell extracts were analyzed by Western blotting with monoclonal antibody 12CA5 against the aminoterminal epitope-tag on the mutant TBPs. The region of the gel with TBP is shown. Results for C176R and P247E were from a separate transfection experiment, with the wt hm3 control shown immediately to the left.

1; Figs. 1B, 8A|. These results are perfectly consistent with the recent crystal structures of yeast TFIIA deletion mutant-core TBP-TATA box DNA complexes (Geiger et al. 1996; Tan et al. 1996; Fig. 6). Residues A184, N189, E191, and R205 are conserved between the yeast and human proteins, and the equivalent yeast amino acid side chains each make contacts with TFIIA in the yeast protein crystal structures. Substitutions A184E, N189E, and E191R block formation of the TA complex even at high TFIIA concentration (Fig. 8A), although these mutant TBPs can form DNA complexes with TFIIB (Fig. 1B). Mutant R205E formed detectable TA complex, although to a significantly lesser extent than wt hm3 (Fig. 8A). Substitutions in surface residues at the top of the first TBP repeat (TBP helix 2, R231E, R235E, R239S), in which earlier reports indicated possible contacts with TFIIA (Buratowski and Zhou 1992; Lee et al. 1992; Tang et al. 1996), did not affect TFIIA binding in the gel mobility shift assay (Fig. 1B, 8A). (Note that the lowest concentration of TFIIA used in the gel mobility shift assay with these mutants was just sufficient to shift wt hm3 (see Fig. 8A, lower right). This indicates that the affinity of these mutants for TFIIA was within twofold of wt $\mathrm{hm} 3$ as measured by the gel mobility shift assay.) However, several of these mutations did reduce TBP binding in a GST-TFIIA column-binding assay (Table 1). Consequently, mutations in this region of the molecule may have small effects on the affinity for TFIIA, but we find that they have much less significant effects than muta- tions on the upstream surface of the first repeat (Fig. 5), where TBP contacts TFIIA in the crystal structures (Fig. 6).

Mutants R205E, E191R, and N189E had basal in vitro transcription activities similar to wt hm3 (Table 1; Fig. 7). These results are consistent with earlier biochemical studies showing that TFIIA is not required for basal in vitro transcription in reactions with TBP and purified transcription factors (Sayre et al. 1992; Sun et al. 1994). These mutants, however, had $\leqslant 5 \%$ the activity of wt $\mathrm{hm} 3$ for transcription activated by GAL4-VP16 or GALl4-E1A in vivo. This phenotype is similar to the yeast TBP double mutant N2-1, characterized by Stargell and Struhl (1995), which is defective for binding to TFIIA in vitro and for supporting activated transcription in vivo, but which does support in vivo transcription from unregulated yeast promoters. Mutants R231E, R235E, R239S, and P247E on the upper surface of the first repeat (Fig. 4) were also extremely defective for supporting activated transcription in vivo (Table 1; Fig. 2), yet had high activity for basal in vitro transcription (Fig. 7).

\section{Discussion}

Our systematic mutational analysis of the TBP surface revealed four epitopes in which single substitutions in any of two to four neighboring surface residues significantly impair the ability of TBP to support activated transcription in vivo. Two of these epitopes represent surfaces of TBP that bind the general transcription factors TFIIA and TFIIB, respectively. It is likely that the remaining two epitopes also represent TBP surfaces that interact with proteins required for activated transcription in vivo. The TFIIA and TFIIB interaction surfaces are of similar size to the surface of $E$. coli CAP protein that interacts with the $\alpha$ subunit of $E$. coli RNA polymerase at the lac promoter (Y. Zhou et al. 1993; Busby and Ebright 1994). As such, these interaction surfaces are large enough to determine specific interactions in the preinitiation complex, but small enough to be sufficiently weak to allow the preinitiation complex to dissociate following initiation.

\section{The TFIIA interaction epitope}

Our identification of TBP mutations that inhibit TFIIA binding are perfectly consistent with the recent crystal structures of complexes of the core of yeast TBP, TATAbox DNA, and viable deletion mutants of yeast TFIIA (Geiger et al. 1996; Tan et al. 1996). The yeast TBP residues equivalent to the critical human TBP residues R205, N189, A184, and E191, in which substitutions inhibited TFIIA binding, all contact TFIIA in the crystal structure models. The crystal structure models also suggest contacts between TFIIA and side chains of TBP residues equivalent to human residues $\mathrm{K} 181, \mathrm{~L} 185, \mathrm{R} 188$, A190, Y192, N193, R203, and I204. Our results with substitutions at K181, L185, and N193 (Table 1; Fig. 8A) suggest that these residues make less significant contributions to the energetics of the interaction than R205, 


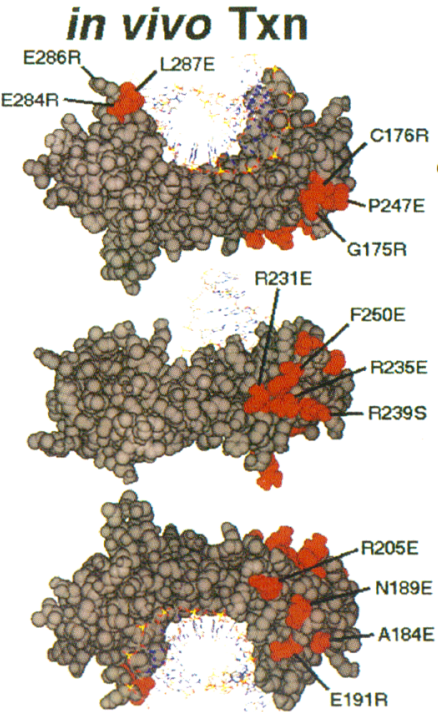

\section{TFIIB binding}
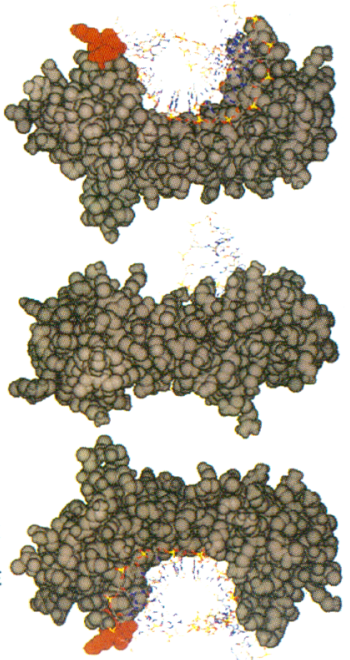

\section{TFIIA binding}

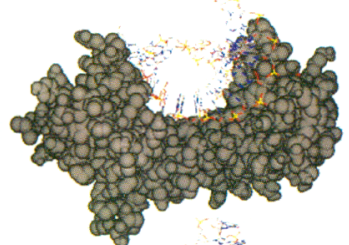

Figure 5. Positions of critical residues on the surface of TBP. Residues where mutations severely depress function are highlighted in red on space filling models of $A r$ abidopsis thaliana TBP. The upstream surface of TBP is shown at the bottom; the molecule is rotated $90^{\circ} \mathrm{C}$ in the middle of the figure to show the top, and then another $90^{\circ} \mathrm{C}$ at the top to show the downstream surface. The first column highlights mutations that reduce in vivo transcription activated by Gal4-E1A to $<20 \%$ of wt $\mathrm{hm} 3$. The middle column highlights residues in which mutations severely inhibit binding to TFIIB and the right column mutations that severely inhibit binding to TFIIA.

N189, A184, and E191. Comparisons between these radical mutations, however, are complicated because they may both eliminate interactions of the wild-type side chains and introduce repulsive forces into a protein-protein interface. We cannot draw conclusions about the significance of contacts with R188, A190, or Y192 because our substitutions at these positions prevented DNA binding even in the presence of TFIIA and TFIIB, probably by causing significant changes in the conformations of the mutant TBPs. We did not mutagenize I204 because the side chain is largely buried. Interpretation of the reduced gel mobility shift activity of mutant R203E is complicated by the fact that the normal arginine at this position also contacts a phosphate in TATA-box DNA and, therefore, contributes to the stability of the TBP-DNA interaction (Kim and Burley 1995). However, this mutant did form a gel mobility shift complex with both TFIIA and TFIIB (Table 1), suggesting that it is properly folded, and it was reduced in binding to a GSTTFIIA column (Table 1), as predicted by the crystal structure models.

In vitro studies have been somewhat equivocal about the function of TFIIA. TFIIA had no affect on basal transcription in reactions with TBP (Sun et al. 1994), but was
TBP-TFIIB-DNA

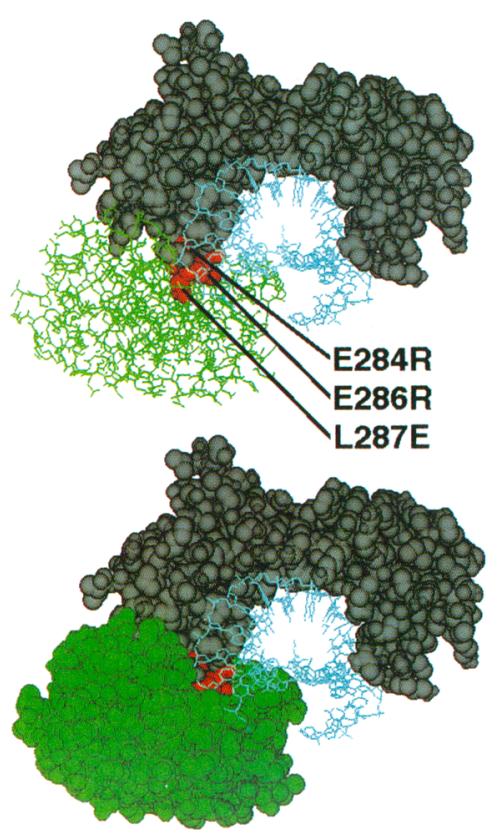

TBP-TFIIA-DNA
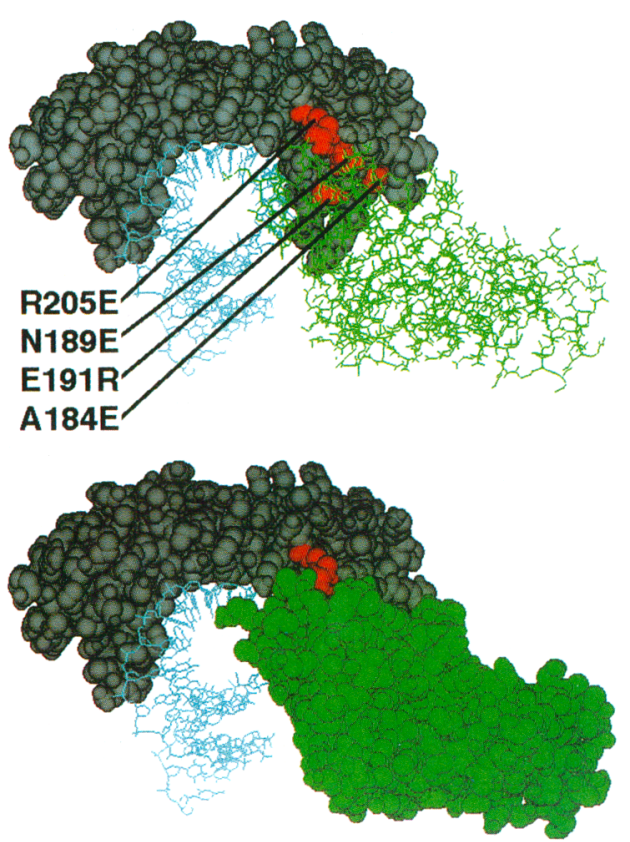

Figure 6. Structures of the TBP-TFIIBDNA and TBP-TFIIA-DNA complexes with TBP residues highlighted where $\mathrm{mu}$ tations inhibit complex formation. Arabidopsis TBP is present in the TFIIB complex (Nikolov et al. 1995), and S. cerevisiae TBP is in the TFIIA complex (Geiger et al. 1996). The highlighted TBP residues are visible in the upper portion of the figure where TFIIB and TFIIA are shown with wire diagrams. The space-filling models of TFIIB and TFIIA in the lower portion of the figure almost completely obscure the highlighted residues that are buried in the protein-protein interfaces. 

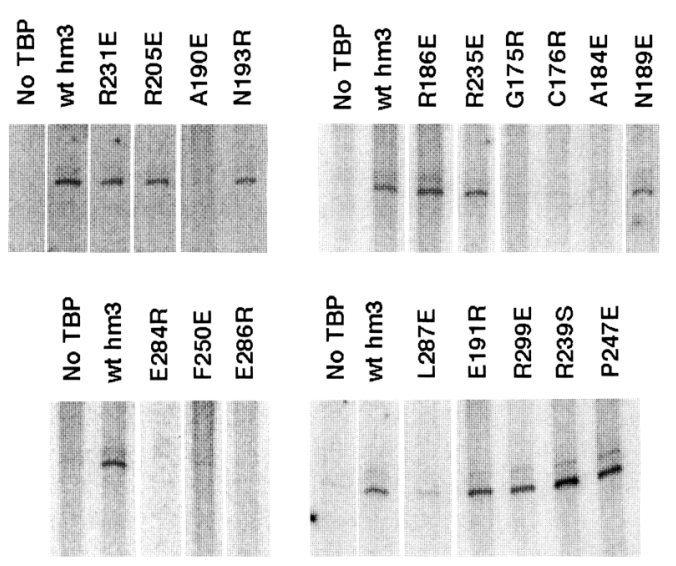

Figure 7. Basal in vitro transcription. Transcription was performed as described in Materials and Methods. For each mutant, control reactions without added TBP and with wt hm 3 from the same gel and same exposure time are shown to the left.

either required for (DeJong et al. 1994; Ozer et al. 1994), or stimulated (Sun et al. 1994; Yokomori et al. 1994; Kang et al. 1995) basal transcription reactions with TFIID. In some studies TFIIA was required for activated transcription (DeJong et al. 1994; Ozer et al. 1994), whereas in others it merely stimulated activated transcription a fewfold (Sun et al. 1994; Yokomori et al. 1994; Kang et al. 1995). Like TFIID TAFs, TFIIA was not required for activated transcription in reactions with the yeast holoenzyme (Koleske and Young 1994; T. Kim et al. 1994). Yet, the genes encoding the subunits of yeast TFIIA are required for viability (Ranish et al. 1992), and shifting yeast cells with temperature-sensitive mutations in TFIIA to the nonpermissive temperature causes a drop in Pol II transcription (Kang et al. 1995).

Stargell and Struhl (1995) isolated a yeast TBP mutant defective in supporting transcriptional activation in vivo by acidic activators but not constitutive transcription and found that it was also defective in binding TFIIA. These, plus other studies, led them to conclude that the interaction between TBP and TFIIA is required for activation by acidic activators in vivo (Stargell and Struhl 1995). Our results with human TBP mutants R205E, E191R, and N189E amply confirm this conclusion. As discussed above, these mutations occur in the TBPTFIIA interface and inhibit TFIIA binding. They are able to form complexes with TFIIB and support near wildtype levels of in vitro basal transcription, indicating that they make all general transcription factor interactions required for this reaction. Nevertheless, they are severely defective for activated transcription in vivo. Moreover, these mutants are defective for activation by both an acidic (VP16) and a nonacidic (E1A CR3) activation domain. These results imply that the TBP-TFIIA interaction is generally required for transcriptional activation in vivo in mammalian cells.

Although these experiments show that the TBP-TFIIA interaction is required for activated transcription in vivo, they do not reveal how this interaction affects transcription. Earlier experiments indicated that a class of activation domains interact with TFIIA /Ozer et al. 1994; Kobayashi et al. 1996) to stimulate the extent, rate of formation, and stability of TFIIA-TFIID complex assembly on promoter DNA (Wang et al. 1992; Lieberman and Berk 1994; Ozer et al. 1994; Chi et al. 1995). The greatly increased rate of assembly may enhance transcription by protecting assembling complexes from inhibitory competing reactions in vivo, such as ATP-dependent dissociation by Mot 1 (Auble et al. 1994) or formation of inactive complexes with TBP-binding inhibitors such as NC2/Drl (Yeung et al. 1994; Kim et al. 1995). TFIIATBP complexes are resistant to both of these inhibitory mechanisms. Activators also induce a conformational change in TFIIA-TFIID-promoter complexes (Lieberman and Berk 1994; Chi et al. 1995; Shykind et al. 1995), visualized by strong nuclease hypersentitivity near the transcription start site of some promoters (Lieberman and Berk 1994; Chi et al. 1995). This appears to be an activated conformation of the complex because it correlates with high initiation rates when the remaining transcription factors and Pol II are added. Consequently, the TFIIA-TBP interaction may be required for activators to stimulate the assembly of preinitiation complexes and to induce structural changes in the complex that increase the rate of initiation.

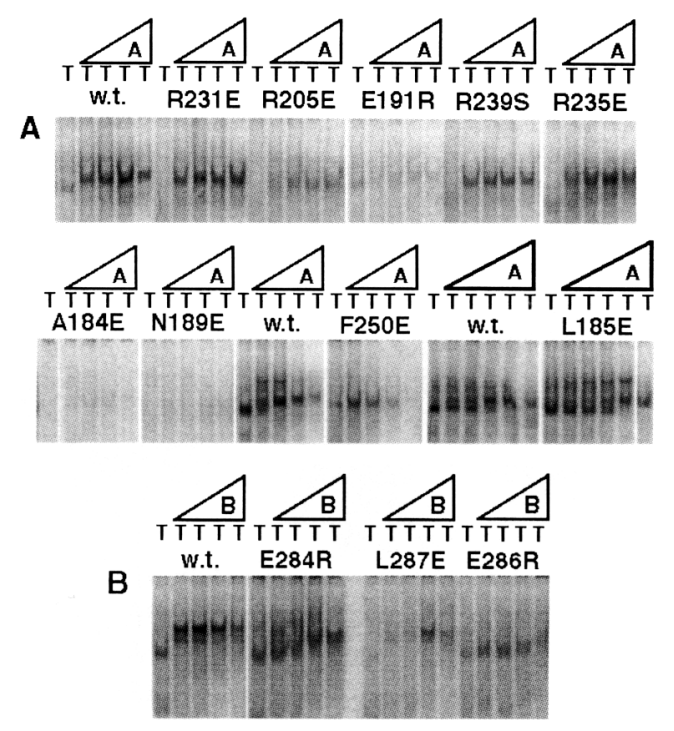

Figure 8. Gel mobility-shift assay titrations. $\{A \mid$ For wt hm3 and each mutant (except L185E) five lanes show (from left to right) binding with TBP alone (5 ng), and plus 15, 30, 60, and 120 ng of recombinant TFIIA, respectively. For A184E, N189E, and the mutants shown in the top row, the assay performed with wt hm3 is shown at the top left. For F250E and L185E, the wt hm3 assay performed at the same time is shown to the left. For the L185E titration, $0,4,8,15,30$, and 60 ng of rTFIIA were added from left to right. $(B)$ Binding reactions contained mutant or wt $\mathrm{hm} 3 \mathrm{TBP}$ alone (5 ng), and plus 20, 60, 180, and $540 \mathrm{ng}$ recombinant TFIIB, respectively, in lanes from left to right. 


\section{The TFIIB interaction epitope}

The TFIIB interaction surface was first identified in studies of alanine substitutions (Kim et al. 1994, 1995; Tang et al. 1996). Our radical mutations in the same residues identified in these earlier studies (E284R, E286R, L287E) greatly decreased the affinity of TBP for TFIIB, as expected from the crystal structure of a complex of Arabidopsis TBP with the core of human TFIIB (Nikolov et al. 1995). For mutants E284R and E286R, in which ionic interactions between the negatively charged glutamic acid side chains and positively charged groups in TFIIB are replaced with potential ionic repulsions, normal TB complexes were not observed, even at $\sim 30$-fold higher TFIIB concentration than required to form TB complex with wt hm 3 (Fig. 8B). The L287E mutation reduced the affinity for TFIIB $\sim 5$ - to 10-fold (Fig. $8 \mathrm{~B}$ ).

The E284R and E286R mutations blocked in vitro basal transcription under our standard conditions (Fig. 7), yet the E286R mutation caused only a twofold drop in activated in vivo transcription (Table 1; Fig. 3). This surprising result suggests that during in vivo activated transcription initiation, TFIIB makes interactions that stabilize its incorporation into a preinitiation complex in addition to the interactions involved in basal in vitro transcription. For GAL4-VP16 activation, these additional interactions could include the interaction observed in vitro between TFIIB and the VP16 activation domain (Hori et al. 1995; Roberts et al. 1995).

\section{Additional activation epitopes}

Mutations in two other regions on the TBP surface also inhibited activated transcription in vivo (Fig. 5). In interpreting the in vivo results for these mutants, it is critical to determine whether or not these mutations significantly alter the structure of TBP. One test for native protein structure was DNA-binding activity. All of the mutants in these two epitopes (R231E, R235E, R239S, F250E; and G175E, C176R, and P247E/ formed gel mobility shift complexes with TFIIA and TFIIB (Fig. 1B, 8A). Of particular significance regarding the question of $\mathrm{mu}$ tant protein structure, mutants R231E, R235E, R239S, and P247E were functional for basal in vitro transcription (Fig. 7). This important result indicates that these mutants make all the general transcription factor interactions required for this complex reaction. Furthermore, mutants R231E, R235E, R239S, and P247E were expressed at higher level in the transfection assay than mutants $\mathrm{F} 280 \mathrm{E}$ and $\mathrm{L} 185 \mathrm{E}$ that have $\geqslant 70 \%$ wt hm 3 activity (Fig. 3, 4). We conclude that mutants R231E, R235E, R239S, and P247E are severely defective for in vivo transcription because they are defective in making required TBP interactions, not because they are improperly folded or because they are not expressed at sufficient level. Consequently, as for the TFIIA-interaction surface, the TBP surface in which these substitutions occur is required specifically for the response to transcriptional activators. Because mutants G175R and C176R were defective for basal in vitro transcription yet bound TATA- box DNA and formed TA and TB gel mobility shift complexes, they may be defective for TBP interactions with other basal transcription factors.

Based on the examples of the TBP interfaces with TFIIB and TFIIA, these two epitopes probably indicate surfaces that interact with proteins yet to be identified. Obvious candidates include TFIID TAFs that are required for activated transcription in mammalian systems in vitro. Because the TFIID TAFs are stably bound to TBP in TFIID, it is likely that the interaction surface that binds TBP to the TAF complex is larger than the TFIIB or TFIIA interaction surfaces. Consequently, the TAF complex might interact with both of the remaining, closely spaced epitopes. Consistent with this possibility, Tansey et al. (1994) reported that a triple alanine substitution, R231A, R235A, R239A was reduced for binding to isolated TAF250 in an in vitro binding assay. Further studies will be required to determine whether TBP mutations in these regions interfere with assembly of the mutant TBPs into the TFIID complex in vivo.

\section{Implications for the significance of other TBP interactions}

Both the VP16 activation domain and EIA CR3 bind to the isolated human TBP protein in vitro /Stringer et al. 1990; Horikoshi et al. 1991; Lee et al. 1991) As discussed in Results, E1A CR3 and VP16 appear to be different types of activation domains. Because they are chemically distinct, it seems unlikely that they would interact with the identical surface of TBP. Consequently, we anticipated that if the activation domain-TBP interactions observed in vitro contribute to the mechanism of activation in vivo, we would observe some mutations of the TBP surface that would influence E1A and VP16 activation differently, by interfering with the TBP interaction with one of these activation domains and not the other. In an analogous situation, different substitutions in the E. coli RNA polymerase $\alpha$ subunit carboxy-terminal domain have different effects on the transcriptional response to different activators (Busby and Ebright 1994). A striking result of our studies, however, was that the library of TBP mutants responded virtually identically to activation by GAL14-E1A and GALl4-VP16 (Fig. 3). This finding shows that transcriptional activation by both E1A and VP16 requires common interactions with TBP. Although we cannot rule it out, it seems unlikely that the E1A and VP16 activation domains would interact with the identical surface residues of TBP. It seems more likely that the TBP functional epitopes identified in this study are interaction surfaces for a common set of proteins that participate in transcription activated by both activators: TFIIA, TFIIB, and, as hypothesized above, TFIID TAF complexes. In an earlier analysis of TBP mutants, Tansey and Herr (1995) also concluded that the in vitro interaction between VP16 and TBP does not contribute to the mechanism of VP16 activation in vivo.

Alanine substitution at TBP residue E320 decreased the binding of TFIIF to a TFIIA-TBP-TFIIB-DNA complex (TAB complex) in the presence of Pol II, and alanine 
substitutions at E206 and L232 decreased the binding of Pol II to the same TAB complex in the presence of TFIIF (Tang et al. 1996). Examining the effects of substitutions at these residues on in vivo transcription, we found that E206R and L232E were nearly as active as wt hm 3 (Table 1). Consequently, interactions at these residues probably do not contribute greatly to in vivo transcription. Our arginine substitution at E320 produced a TBP molecule that did not bind to DNA in the gel mobility shift assay. Consequently, we cannot draw conclusions about the significance of interactions at this residue.

Fourteen of the 89 mutants we constructed did not form gel mobility shift complexes on TATA-box DNA. As expected from this low DNA-binding activity, none of these mutants were active for in vitro basal transcription (Table 1). Eight of these mutants had very low in vivo activity, as anticipated. However, six of these mutant TBPs that did not bind to a TATA box in vitro had in vivo activities of $>20 \% \mathrm{wt} \mathrm{hm} 3$ (Table 1 ). Tansey et al. (1994) also observed TBP mutants with greatly decreased TATA-box-binding activity that, nonetheless, were active in vivo. These results suggest that compared with basal in vitro transcription, additional interactions occur during in vivo activated transcription that stabilize the incorporation of these mutant TBPs into a preinitiation complex. In related results Arndt et al. (1995) and Lee and Struhl (1995) found that a class of yeast TBP mutants selected to be deficient in activated, but not basal, transcription have mutations that decrease the affinity of TBP for TATA-box DNA. All these results are consistent with the model that activators function in part by promoting assembly of the preinitiation complex (Gaynor and Berk 1983).

Stargell and Struhl (1996) recently reported the characterization of four yeast TBP mutants (F148H, T153I, E236P, and F237D) specifically defective for the ability to support activated transcription in vivo, but wild-type for the ability to support transcription from unregulated promoters and for transcription by Pol I and Pol III. We mutated human TBP residues at three of the positions equivalent to these yeast residues in the TBP core domain. Human TBP mutants F246E and L251E (equivalent to yeast F148 and T153, respectively) had only modest effects on in vivo function in our assays, whereas mutant G334R (equivalent to yeast E236) was fully functional. Our failure to observe significant phenotypes for these human TBP mutations may be because our assays measured transcription from potently activated promoters with four or five binding sites for powerful viral activators, potentially masking the effects of all but the most deleterious TBP mutations. The yeast mutants fell into two classes as determined by whether their defects could be suppressed by recruiting the mutant TBP to a promoter through fusion to a LexA DNA-binding domain. Mutant T153I was fully suppressed and F148H was partially suppressed, whereas the mutations near the carboxyl terminus of TBP were not surpressed by fusion to the LexA DNA-binding domain. The yeast residues T153 and F148 lie near the epitopes defined by our mutations on the upper surface of the first TBP repeat
(Fig. 5) and may influence interactions with yeast factors homologous to the human factors that we postulate interact with these epitopes. Because the yeast mutations can be suppressed by recruiting them to a promoter via the LexA DNA-binding domain fusion, the factors that interact with this region of TBP may function by helping to bind wild-type TBP to activated promoters, as suggested by Stargell and Struhl (1996).

Our strategy to identify functionally important regions on TBP's surface was to substitute wild-type surface residues with amino acids having radically different side chains. Our reasoning was that such mutations would be more likely to severely impair protein-protein interactions and result in significant phenotypes than the frequently used approach of alanine substitution. Our strategy was effective in identifying a surface of TBP that interacts with TFIIA. In contrast, alanine substitutions of single residues in the TFIIA interaction surface did not significantly alter the affinity of TBP for TFIIA as measured in gel mobility shift assays (Tang et al. 1996). This may be because there are a large number of interactions in the TFIIA-TBP interface, many of them with polypeptide backbone atoms that are not altered by amino acid substitutions (Geiger et al. 1996; Tan et al. 1996). Substitution by alanine eliminates interactions beyond the $\beta$-carbon of the side chain substituted, and this apparently did not reduce the energy of binding sufficiently to observe a significant decrease in affinity. In contrast, substitution of a charged residue with a large residue of opposite charge, and substitution of short or hydrophobic side chains with a large charged side chain both eliminates interactions made by the wild-type side chain and may introduce repulsive forces into a proteinprotein interface. In the case of the TBP-TFIIA interaction, the resulting dramatic decreases in affinity were readily detected. In a second contrasting situation, whereas we observed strong phenotypes for individual mutations of basic residues in TBP helix 2 (R231E, R235E, and R239S), Tansey et al. (1994) found that a triple alanine substitution of these same residues in a single mutant (mutant H2, R231A+R235A+R239A) was reduced to only $50 \%$ of the activity of wt hm 3 in their in vivo assay.

Surprisingly, alternative substitutions in one of the epitopes we defined as being required for Pol II transcription (R231, R235, and F250) specifically affect Pol III transcription in vivo in yeast (mutants in $S$. cerevisiae TBP K133T, K133S, R137W, R137C, F152G, F152E, Cormack and Struhl 1993). These mutations in yeast TBP were selected to generate temperature-sensitive growth of yeast cells, and can be suppressed by overexpression of the Pol III TAF, Brf1 (Cormack and Struhl 1993). It seems likely that the TAFs and general transcription factors specific for each of the three eukaryotic nuclear RNA polymerases evolved from proteins that functioned with a single complex RNA polymerase in a common ancestor of all eukaryotes, and as presently represented by organisms in the kingdom Archaea (Baumann et al. 1995; Langer et al. 1995; Thomm 1996). The proteinprotein interfaces with TBP in these initiation com- 
plexes probably were conserved as the distinct Pol I, Pol II, and Pol III systems evolved. Based on this evolutionary argument and the results of Cormack and Struhl (1993) we suggest that residues R231, R235, and F250 contribute to the TBP surface that interacts with a domain of Brf1 in the Pol III factor TFIIIB and an evolutionarily related domain of a Pol II TAF in TFIID. We suggest that selection of temperature-sensitive TBP mutants in $S$. cerevisiae yielded substitutions in this interface that weaken the TBP-Brfl interaction just to the extent that it is broken at the nonpermissive temperature, but not at the lower permissive temperature. We propose that these substitutions are also in the interface with a yeast Pol II TAF, but that they do not weaken the interaction sufficiently to produce a rapid shut-off phenotype for Pol II functions following a shift to the nonpermissive temperature. In contrast, we propose that our (for the most part) more radical substitutions prevent the binding of mammalian Pol II TAFs, and we would predict the binding of the Pol III TAF, Brf1 as well. Further studies are required to test these ideas.

The drawback of radical substitutions is that they may alter the overall conformation of the protein domain being analyzed. For TBP, 14/89 $\sim 15 \%)$ of the radical mutations introduced into surface residues inhibited TBPDNA binding. For mutations in TBP residues that do not interact directly with DNA, we interpret the loss of DNA-binding activity to indicate a significant change in protein conformation. However, if mutants that distort overall protein conformation can be distinguished from those that do not, in this case by assaying TBP DNAbinding activity, then such mutants do not confuse the interpretation of the remaining, more meaningful mutants. Radical mutations in protein surface residues have the potential of introducing repulsive forces into protein-protein interfaces. This strategy may be a generally effective method to probe structure-function relationships of polypeptides incorporated into multiprotein complexes, such as the transcription preinitiation complex, in which eliminating a single side chain's interactions through alanine substitution may not decrease the stability of the overall complex sufficiently to produce a clear phenotype.

\section{Materials and methods}

\section{Mutagenesis of TBP}

Altered binding site human TBP (hTBPm3) (Strubin and Struhl 1992) was modified by PCR to include one or two copies of the 9-amino-acid $\mathrm{HAl}$ flu epitope at the amino terminus (hTBPm3e). This hTBPm3e coding region was cloned into pBlueScript (Stratagene), sequenced, and used for for oligonucleotide-directed mutagenesis by use of Amersham Sculptor. Mutant plasmids were sequenced and restriction mapped.

\section{Purification of TBP mutants}

To facilitate mutant TBP purification, each mutant coding region was cloned into a $\mathrm{pQE}-30$ (Qiagen) expression vector so that a $6 \mathrm{His}$ peptide was inserted before the first methionine of human TBP. To accomplish this, the nucleotide sequence en- coding the first 184 amino acids of wild-type TBP was generated by PCR to contain a BamHI site at the amino terminus plus SstII and HindIII sites next to the native DraIII site of TBP. This fragment was cloned into the BamHI-HindIII site of pQE-30 to generate pQE-30TBPA. The DraIII-SstII fragment encoding most of the carboxy-terminal domain of each mutant TBP was then cloned between the DraIII and SstII site of pQE-30TBP $\Delta$ to regenerate full-length TBP mutants with a $6 \times$ His tag. For mutants at amino acid positions 156-184, which are amino-terminal to the DraIII site, transfer was accomplished in a two-step cloning strategy. First, a PstI-HindIII fragment from TBP was cloned into the PstI-HindIII site of pQE-30TBPA. Then the PstIPstI fragments of the mutant TBPs were cloned into the PstI site of this vector and the orientation was confirmed by restriction analysis.

Mutant TBPs were then purified by heparin-Sepharose followed by $\mathrm{Ni}^{+2}$-NTA-chromatography. The pQE-30 vectors encoding each mutant TBP were transformed into $E$. coli strain M15. Bacteria were grown in $500 \mathrm{ml}$ of $2 \times$ Tryptone Yeast Extract media (TYE) (DIFCO) to an $\mathrm{OD}_{600}$ of $\sim 0.7$ at $37^{\circ} \mathrm{C}$. Cells are then induced with $1 \mathrm{~mm}$ isopropyl- $\beta$-D-thiogalactoside (IPTG) and grown for $45 \mathrm{~min}$ at $30^{\circ} \mathrm{C}$. Cells were then pelleted and resuspended in $30 \mathrm{ml}$ of $\mathrm{D}$ buffer [ $20 \mathrm{~mm}$ HEPES at $\mathrm{pH} 7.9$, $20 \%$ glycerol, $0.2 \mathrm{~mm}$ EDTA, $10 \mathrm{~mm} \beta$-mercaptoethanol, and 0.5 $\mathrm{mM}$ phenylmethylsulfonyl fluoride (PMSF)] containing $100 \mathrm{mM}$ $\mathrm{KCl}\left(\mathrm{D}_{100}\right)$. Cells were sonicated, debris was removed by centrifugation, and His-tagged TBP mutants were purified from the soluble extract by binding the supernatant in batch to heparinSepharose (Pharmacia; $1 \mathrm{ml}$ of heparin per 5-10 $\mathrm{mg}$ of protein) at $4^{\circ} \mathrm{C}$ for $1 \mathrm{hr}$. The resin was washed once with $D_{100}$ and loaded into a column that was washed with $\mathrm{D}$ buffer containing 300 $\mathrm{mM} \mathrm{KCl}\left(\mathrm{D}_{300}\right)$ and eluted with $\mathrm{D}$ buffer containing $1 \mathrm{M} \mathrm{KCl}$. The eluted protein was diluted with $\mathrm{D}$ buffer to a final concentration of $300 \mathrm{~mm} \mathrm{KCl}$. This protein fraction was then bound in batch for $1 \mathrm{hr}$ at $4^{\circ} \mathrm{C}$ to $1 \mathrm{ml}$ of $\mathrm{Ni}^{+2}$-NTA-Agarose (Qiagen) that was pre-equilibrated in $\mathrm{D}_{300}$. The beads were then washed once with $\mathrm{D}_{300}$ and loaded into a column that was washed with $\mathrm{D}_{300}$ containing $5 \mathrm{~mm}$ imidazole. Finally, the columns were eluted with $400 \mu \mathrm{D}_{300}$ containing $100 \mathrm{~mm}$ imidazole. The purified protein was then dialyzed for $4 \mathrm{hr}$ at $4^{\circ} \mathrm{C}$ in $\mathrm{D}_{300}$. Protein concentrations were determined by Bradford assay. Equivalent masses of different mutant TBP preparations were used in gel mobility shift assays and in vitro transcription assays as indicated below.

\section{Gel mobility shift assays}

Gel mobility shift assays contained $5 \mathrm{ng}$ of mutant TBP or wt $\mathrm{hm} 3,0.4 \mathrm{ng}$ of ${ }^{32} \mathrm{P}$-labeled double-stranded DNA (37 mer) with the adenovirus 2 major late promoter TATA box and, where indicated, $15 \mathrm{ng}$ of recombinant TFIIA or/and $15 \mathrm{ng}$ of recombinant TFIIB in $12.5 \mu l 40 \mathrm{~mm} \mathrm{KCl}, 5 \mathrm{~mm} \mathrm{MgCl}_{2}, 10 \mathrm{~mm}$ HEPES at $\mathrm{pH} 7.9,10 \mathrm{mM} \beta$-mercaptoethanol, $20 \mu \mathrm{g} / \mathrm{ml}$ poly[d/G-C)], $500 \mu \mathrm{g} / \mathrm{ml} \mathrm{BSA}, 10 \%$ glycerol, $0.1 \mathrm{~mm}$ EDTA. Reactions were incubated for $30 \mathrm{~min}$ at $37^{\circ} \mathrm{C}$ and products were resolved on a $5 \%$ polyacrylamide gel in $45 \mathrm{~mm}$ Tris, $45 \mathrm{~mm}$ boric acid at $\mathrm{pH}$ 8.3, and 1 mM EDTA.

In vivo function assays

In vivo function of each TBP mutant was assayed during transient transfection of COS cells.

\section{TGTAAA-box reporter plasmids}

The reporter derived from the $\beta$-retinoic acid receptor promoter region was pGal4-M1-Luc (Keveaney et al. 1993). The second reporter plasmid, p4xGalc-fosTGTluc, was derived from 
c-fos(-56) [4xGAL] (Tansey et al. 1994) by replacing the CAT gene with luciferase.

\section{Mutant TBP mammalian expression vector}

Wt hm3 and each mutant TBP were expressed by use of the pSR $\alpha$ MSVtkneo vector (Muller et al. 1991) that replicates from an SV40 origin in COS cells and expresses mRNA from the strong SR $\alpha$ hybrid promoter. Wt hm 3 and mutant coding regions were transferred as an EcoRI-HindIII fragment from each mutant pBlueScript to pSR $\alpha \mathrm{MSV}$ tkneo.

\section{GAL4-activator vectors}

pGAL4-E1A (Martin et al. 1990) expresses yeast GAL4 1-147 fused to Ad2 ElA 121-223 (conserved region 3) from the SV40 early promoter. GAL4-VP16 was expressed from the SV40 early promoter by use of pSGVP16 (Sadowski et al. 1988). $\beta$-galactosidase expressed from pCH110 (Hall et al. 1983) was assayed to normalize transient transfection assays.

\section{Transient transfection assays}

Three micrograms of mutant TBP expression vector, $5 \mu \mathrm{g}$ of reporter plasmid (p4xGALc-fosTGTluc or pGAL4-M1-Luc), 1 $\mu \mathrm{g}$ of pGAL4-ElA or $0.1 \mu \mathrm{g}$ of pSGVP16, $1 \mu \mathrm{g}$ of pCH110, and salmon sperm DNA up to $10 \mu \mathrm{g}$ was added as a $\mathrm{CaPO}_{4}$ precipitate in $0.5 \mathrm{ml}$ to a $60-\mathrm{mm}$ plate of COS cells plated the previous day. Cells were harvested $48 \mathrm{hr}$ later with $200 \mu \mathrm{l}$ of lysis buffer (Promega, Luciferase Assay System). Luciferase was assayed by use of the Monolight 2010 luminomitor (Analytical Luminescence Laboratory) with $5 \mathrm{sec}$ measurements with the Promega Luciferase Assay Substrate. $\beta$-Galactosidase was assayed by ONPG hydrolysis. Luciferase assays were normalized by dividing luciferase units by $\beta$-galactosidase units. The background control was from a transfection in which the TBP expression vector was replaced by the same vector expressing an inactive, truncated form of hm3 (deleted at the StuI site). Reported units are normalized luciferase units minus background as a percentage of the activity observed with wt hm3.

\section{In vitro basal transcription}

For in vitro basal transcription, $20 \mathrm{ng}$ of mutant TBP (or wt hm3) and 300 of ng plasmid TGL + 3C-1A (Kaufmann et al. 1996) were incubated in $20 \mu \mathrm{l}$ of $50 \mathrm{mM} \mathrm{KCl}, 4 \mathrm{mM} \mathrm{MgCl}_{2}, 10 \mathrm{~mm}$ Tris, 10 $\mathrm{mM}$ HEPES at $\mathrm{pH} 7.9,1 \mathrm{~mm}$ DTT, $100 \mu \mathrm{g} / \mathrm{ml}$ BSA, $13 \%$ glycerol at $30^{\circ} \mathrm{C}$ for $20 \mathrm{~min}$, then $60 \mathrm{mg}$ of heat-treated HeLa nuclear extract protein, ATP and CTP to $0.9 \mathrm{~mm}$, UTP to $20 \mathrm{~mm}, 10 \mu \mathrm{Ci}$ $\alpha^{-32} \mathrm{P}$ UTP, 8 units RNase inhibitor (Boehringer Mannheim) were added (final $45 \mu \mathrm{l}$ ) and incubation continued for $60 \mathrm{~min}$. RNase T1 (10 units) was added for $20 \mathrm{~min}$, then SDS and tRNA carrier and products were phenol-chloroform extracted, ethanol precipitated, and analyzed on a $9 \% 7 \mathrm{M}$ urea polyacrylamide gel. Counts in specific transcript were quantitated by use of a Molecular Dynamics PhosphorImager. Template TGL $+3 \mathrm{C}-1 \mathrm{~A}$ has no significant initiator function. In this assay, similar levels of transcription were observed by use of template TGL $+3 \mathrm{C}-1 \mathrm{~A}$ and template TGLwt containing the wild-type initiator from the TdT gene (Kaufmann et al. 1996). This indicates that TBP does not reassociate with TAFs under these conditions, because in transcription reactions with TFIID, $\sim 5$ times more transcription is observed with the TGLwt template than with the TGL + 3C-1 A template (Kaufmann et al. 1996).

\section{Acknowledgments}

This work was supported by grant CA25235 from the U.S. Public Health Service. G.O.B. was supported by training grant GM07104 and L.M. by training grant CA-09056. We thank Carol Eng for excellent technical assistance.

The publication costs of this article were defrayed in part by payment of page charges. This article must therefore be hereby marked "advertisement" in accordance with 18 USC section 1734 solely to indicate this fact.

\section{References}

Arndt, K.M., S. Ricupero-Hovasse, and F. Winston. 1995. TBP mutants defective in activated transcription in vivo. EMBO J. 14: 1490-1497.

Auble, D.T., K.E. Hansen, C.G. Mueller, W.S. Lane, J. Thorner, and S. Hahn. 1994. Motl, a global repressor of RNA polymerase II transcription, inhibits TBP binding to DNA by an ATP-dependent mechanism. Genes \& Dev. 8: 1920-1934.

Baumann, P., S.A. Qureshie, and S.P. Jackson. 1995. Transcription: New insights from studies on Archaea. Trends Genet. 11: 79-283.

Bucher, P. 1990. Weight matrix descriptions of four eukaryotic RNA polymerase II promoter elements derived from 502 unrelated promoter sequences. I. Mol. Biol. 212: 563-578.

Buratowski, S. and H. Zhou. 1992. Transcription factor IID mutants defective for interaction with transcription factor IIA. Science 255: 1130-1132.

. 1993. Functional domains of transcription factor TFIIB. Proc. Natl. Acad. Sci. 90: 5633-5637.

Buratowski, S., S. Hahn, L. Guarente, and P.A. Sharp. 1989. Five intermediate complexes in transcription initiation by RNA polymerase II. Cell 56: 549-561.

Burley, S.K. and R.G. Roeder. 1996. Biochemistry and structural biology of transcription factor IID (TFIID). Annu. Rev. Biochem. 65: 769-799.

Busby, S. and R.H. Ebright. 1994. Promoter structure, promoter recognition, and transcription activation in prokaryotes. Cell 79: 743-746.

Chatterjee, S. and K. Struhl. 1995. Connecting a promoter bound protein to the TATA-binding protein overrides the need for a transcriptional activation domain. Nature 374: 820-822.

Chi, T., P. Lieberman, K. Ellwood, and M. Carey. 1995. A general mechanism for transcriptional synergy by eukaryotic activators. Nature 377: 254-257.

Cormack, B.P. and K. Struhl. 1993. Regional codon randomization: Defining a TATA-binding protein surface required for RNA polymerase III transcription. Science 262: 244-248.

Cress, W.D. and S. Triezenberg. 1991. Critical structural elements of the VP16 transcriptional activation domain. Science 251: 87-90.

Davison, B.L., J.-M. Egly, E.R. Mulvihill, and P. Chambon. 1983. Formation of stable preinitiation complexes between eukaryotic class B transcription factors and promoter sequences. Nature 301: 680-686.

DeJong, J., R. Bernstein, and R.G. Roeder. 1995. Human general transcription factor TFIIA: Characterization of a cDNA encoding the small subunit and requirement for basal and activated transcription. Proc. Natl. Acad. Sci. 92: 3313-3317.

Dynlacht, B.D., T. Hoey, and R. Tjian. 1991. Isolation of coactivators associated with the TATA-binding protein that mediate transcriptional activation. Cell 66: 563-576. 
Gaynor, R.B. and A.J. Berk. 1983. Cis-acting induction of adenovirus transcription. Cell 33: 683-693.

Ge, H. and R.G. Roeder. 1994. Purification, cloning, and characterization of a human coactivator, PC4, that mediates transcriptional activation of class II genes. Cell 78: 513-523.

Geiger, J.H., S. Hahn, S. Lee, and P.B. Sigler. 1996. TFIIA/TBP/ DNA complex. Science 272: 830-836.

Goodrich, J.A. and R. Tiian. 1994. TBP-TAF complexes: Selectivity factors for eukaryotic transcription. Curr. Opin. Cell Biol. 6: 403-409.

Ha, I., S. Roberts, E. Maldonado, X. Sun, L.U. Kim, M. Green, and D. Reinberg. 1993. Multiple functional domains of human transcription factor IIB: Distinct interactions with two general transcription factors and RNA polymerase II. Genes \& Dev. 7: 1021-1032.

Hall, C.V., P.E. Jacob, G.M. Ringold, and F. Lee. 1983. Expression and regulation of Escherichia coli lacZ gene fusions in mammalian cells. J. Mol. Appl. Gen. 2: 101-109.

Hernandez, N. 1993. TBP, a universal eukaryotic transcription factor? Genes \& Dev. 7: 1291-1308.

Hisatake, K., R.G. Roeder, and M. Horikoshi. 1993. Functional dissection of TFIIB domains required for TFIIB-TFIID-promoter complex formation and basal transcription activity. Nature 363: 744-747.

Hori, R., S. Pyo, and M. Carey. 1995. Protease footprinting reveals a surface on transcription factor TFIIB that serves as an interface for activators and coactivators. Proc. Natl. Acad. Sci. 92: 6047-6051.

Horikoshi, N., K. Maguire, A. Kralli, E. Maldonado, D. Reinberg, and R. Weinmann. 1991. Direct interaction between adenovirus E1A protein and the TATA box binding transcription factor IID. Proc. Nat1. Acad. Sci. 88: 5124-5128.

Kaiser, K., G. Stelzer, and M. Meisterernst. 1995. The coactivator p15 (PC4) initiates transcriptional activation during TFIIA-TFIID-promoter complex formation. EMBO I. 14: 3520-3527.

Kang, J.J., D.T. Auble, J.A. Ranish, and S. Hahn. 1995. Analysis of the yeast transcription factor TFIIA: Distinct functional regions and a polymerase II-specific role in basal and activated transcription. Mol. Cell. Biol. 15: 1234-1243.

Kaufmann, J., C.P. Verrijzer, J. Shao, and S.T. Smale. 1996. CIF, an essential cofactor for TFIID-dependent initiator function. Genes \& Dev. 10: 873-886.

Keaveney, M., A. Berkenstam, M. Feigenbutz, G. Vriend, and H.G. Stunnenberg. 1993. Residues in the TATA-binding protein required to mediate a transcriptional response to retinoic acid in EC cells. Nature 365: 562-566.

Kim, J.L. and S.K. Burley. 1994. 1.9 A resolution refined structure of TBP recognizing the minor groove of TATAAAAG. Nature Struct. Biol. 1: 638-653.

Kim, T.K., S. Hashimoto, R.J.I. Kelleher, P.M. Flanagan, R.D. Kornberg, M. Horikoshi, and R.G. Roeder. 1994. Effects of activation-defective TBP mutrations on transcription initiation in yeast. Nature 369: 252-255.

Kim, T.K., Y. Zhao, H. Ge, R. Bernstein, and R.G. Roeder. 1995. TATA-binding protein residues implicated in a functional interplay between negative cofactor NC2 (Dr1) and general factors TFIIA and TFIIB. J. Biol. Chem. 270: 10976-10981.

Kim, Y., J.H. Geiger, S. Hahn, and P.B. Sigler. 1993. Crystal structure of a yeast TBP/TATA-box complex. Nature 365: 512-520.

Kim, Y.J., S. Bjorklund, Y. Li, M.H. Sayre, and R.D. Kornberg. 1994. A multiprotein mediator of transcriptional activation and its interaction with the C-terminal repeat domain of RNA polymerase II. Cell 77: 599-608.

Klages, N. and M. Strubin. 1995. Stimulation of RNA polymer- ase II transcription initiation by recruitment of TBP in vivo. Nature 374: 822-823.

Klein, C. and K. Struhl. 1994. Increased recruitment of TATAbinding protein to the promoter by transcriptional activation domains in vivo. Science 266: 280-282.

Kobayashi, N., T.G. Boyer, and A.J. Berk. 1995. A class of activation domains interacts directly with TFIIA and stimulates TFIIA-TFIID-promoter complex assembly. Mol. Cell. Biol. 115: 6465-6473.

Koleske, A.J. and R.A. Young. 1994. An RNA polymerase II holoenzyme responsive to activators. Nature 368: $466-469$.

Langer, D., J. Hain, P. Thuriaux, and W. Zillig. 1995. Transcription in archaea: Similarity to that in eucarya. Proc. Natl. Acad. Sci. 92: 5768-5772.

Lee, M. and K. Struhl. 1995. Mutations on the DNA-binding surface of TATA-binding protein can specifically impair the response to acidic activators in vivo. Mol. Cell. Biol. 15: $5461-5469$.

Lee, W.S., C.C. Kao, G.O. Bryant, X. Liu, and A.J. Berk. 1991. Adenovirus ElA activation domain binds the basic repeat in the TATA box transcription factor. Cell 67: 365-376.

Lee, D.K., J. DeJong, S. Hashimoto, M. Horikoshi, and R.G. Roeder. 1992. TFIIA induces conformational changes in TFIID via interactions with the basic repeat. Mol. Cell. Biol. 12: 5189-5196.

Leuther, K.K., J.M. Salmeron, and S.A. Johnston. 1993. Genetic evidence that an activation domain of GAL4 does not require acidity and may form a $\beta$ sheet. Cell 72: $575-585$.

Lieberman, P.M. and A.J. Berk. 1994. A mechanism for TAFs in transcriptional activation: Activation domain enhancement of TFIID-TFIIA-promoter DNA complex formation. Genes \& Dev. 8: 995-1006.

Luo, Y. and R.G. Roeder. 1995. Cloning, functional characterization, and mechanism of action of the B-cell-specific transcriptional coactivator OCA-B. Mol. Cell. Biol. 15: 41154124.

Martin, K.J., J.W. Lillie, and M.R. Green. 1990. Evidence for interaction of different eukaryotic transcriptional activators with distinct cellular targets. Nature 346: 147-152.

Muller, A.J., J.C. Young, A.M. Pendergast, M. Pondel, N.R. Landau, D.R. Littman, and O.N. Witte. 1991. BCR first exon sequences specifically activate the BCR/ABL tyrosine kinase oncogene of Philadelphia chromosome-positive human leukemias. Mol. Cell. Biol. 11: 1785-1792.

Nikolov, D.B., H. Chen, E.D. Halay, A.A. Usheva, K. Hisatake, D.K. Lee, R.G. Roeder, and S.K. Burley. 1995. Crystal structure of a TFIIB-TBP-TATA-element ternary complex. Nature 377: 119-128.

Ozer, J., P.A. Moore, A.H. Bolden, A. Lee, C.A. Rosen, and P.M. Lieberman. 1994. Molecular cloning of the small $(\gamma)$ subunit of human TFIIA reveals functions critical for activated transcription. Genes \& Dev. 8: 2324-2335.

Ranish, J.A., W.S. Lane, and S. Hahn. 1992. Isolation of two genes that encode subunits of the yeast transcription factor IIA. Science 255: 1127-1129.

Roberts, S.G., B. Choy, S.S. Walker, Y.S. Lin, and M.R. Green. 1995. A role for activator-mediated TFIIB recruitment in diverse aspects of transcriptional regulation. Curr. Biol. 5: 508-516.

Sadowski, I., J. Ma, S. Triezenberg, and M. Ptashne. 1988. GAL4VP16 is an unusually potent transcriptional activator. $\mathrm{Na}$ ture 335: 563-564.

Sayre, M.H., H. Tschochner, and R.D. Kornberg. 1992. Reconstitution of transcription with five purified initiation factors and RNA polymerase II from Saccharomyces cerevisiae. I. Biol. Chem. 267: 23376-23382. 
Shykind, B.M., J. Kim, and P.A. Sharp. 1995. Activation of the TFIID-TFIIA complex with HMG-2. Genes \& Dev. 9: 1354 1365.

Stargell, L.A. and K. Struhl. 1995. The TBP-TFIIA interaction in the response to acidic activators in vivo. Science 269: 75-78.

. 1996. A new class of activation-defective TATA-binding protein mutants: Evidence for two steps of transcriptional activation in vivo. Mol. Cell. Biol. 16: 4456-4464.

Stringer, K.F., C.J. Ingles, and J. Greenblatt. 1990. Direct and selective binding of an acidic transcriptional activation domain to the TATA-box factor TFIID. Nature 345: 783-786.

Strubin, M. and K. Struhl. 1992. Yeast and human TFIID with altered DNA-binding specificity for TATA elements. Cell 68: $721-730$.

Sun, X., D. Ma, M. Sheldon, K. Yeung, and D. Reinberg. 1994. Reconstitution of human TFIIA activity from recombinant polypeptides: A role in TFIID-mediated transcription. Genes \& Dev. 8: 2336-2348.

Tan, S., Y. Hunziker, D.F. Sargent, and T.J. Richmond. 1996. Crystal structure of a yeast TFIIA/TBP/DNA complex. $\mathrm{Na}$ ture 381: 127-134.

Tang, H., X. Sun, D. Reinberg, and R.H. Ebright. 1996. Proteinprotein interactions in eukaryotic transcription initiation: Structure of the preinitiation complex. Proc. Natl. Acad. Sci. 93: 1119-1124.

Tansey, W.P. and W. Herr. 1995. The ability to associate with activation domains in vitro is not required for the TATA box-binding protein to support activated transcription in vivo. Proc. Natl. Acad. Sci. 92: 10550-10554.

Tansey, W.P., S. Ruppert, R. Tiian, and W. Herr. 1994. Multiple regions of TBP participate in the response to transcriptional activators in vivo. Genes \& Dev. 8: 2756-2769.

Thomm, M. 1996. Archaeal transcription factors and their role in transcription initiation. Fems Microbiol. Rev. 18: 159171.

Um, M., C. Li, and J.L. Manley. 1995. The transcriptional repressor even-skipped interacts directly with TATA-binding protein. Mol. Cell. Biol. 15: 5007-5016.

Usheva, A., E. Maldonado, A. Goldring, H. Lu, C. Houbavi, D. Reinberg, and Y. Aloni. 1992. Specific interaction between the nonphosphorylated form of RNA polymerase II and the TATA-binding protein. Cell 69: 871-881.

Wang, W., J.D. Gralla, and M. Carey. 1992. The acidic activator GAL4-AH can stimulate polymerase II transcription by promoting assembly of a closed complex requiring TFIID and TFIIA. Genes \& Dev. 6: 1716-1727.

Webster, L.C. and R.P. Ricciardi. 1991. trans-dominant mutants of ElA provide genetic evidence that the zinc finger of the trans-activating domain binds a transcription factor. Mol. Cell. Biol. 11: 4287-4296.

Xiao, H., J.D. Friesen, and J.T. Lis. 1995. Recruiting TATAbinding protein to a promoter: Transcriptional activation without an upstream activator. Mol. Cell. Biol. 15: 57575761.

Yeung, K.C., J.A. Inostroza, F.H. Mermelstein, C. Kannabiran, and D. Reinberg. 1994. Structure-function analysis of the TBP-binding protein Drl reveals a mechanism for repression of class II gene transcription. Genes \& Dev. 8: 2097-2109.

Yokomori, K., M.P. Zeidler, J.L. Chen, C.P. Verrijzer, M. Mlodzik, and R. Tjian. 1994. Drosophila TFIIA directs cooperative DNA binding with TBP and mediates transcriptional activation. Genes \& Dev. 8: 2313-2323.

Zhou, Q., T.G. Boyer, and A.J. Berk. 1993. Factors (TAFs) required for activated transcription interact with TATA boxbinding protein conserved core domain. Genes \& Dev. 7: 180-187.
Zhou, Y., X. Zhang, and R.H. Ebright. 1993. Identification of the activating region of catabolite gene activator protein $(\mathrm{CAP})$ : Isolation and characterization of mutants of CAP specifically defective in transcription activation. Proc. Natl. Acad. Sci. 90: 6081-6085. 


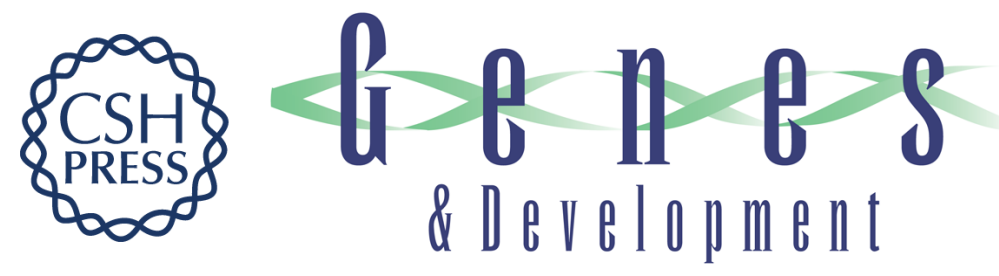

\section{Radical mutations reveal TATA-box binding protein surfaces required for activated transcription in vivo.}

G O Bryant, L S Martel, S K Burley, et al.

Genes Dev. 1996, 10:

Access the most recent version at doi:10.1101/gad.10.19.2491

References This article cites 74 articles, 39 of which can be accessed free at:

http://genesdev.cshlp.org/content/10/19/2491.full.html\#ref-list-1

License

Email Alerting

Service right corner of the article or click here.

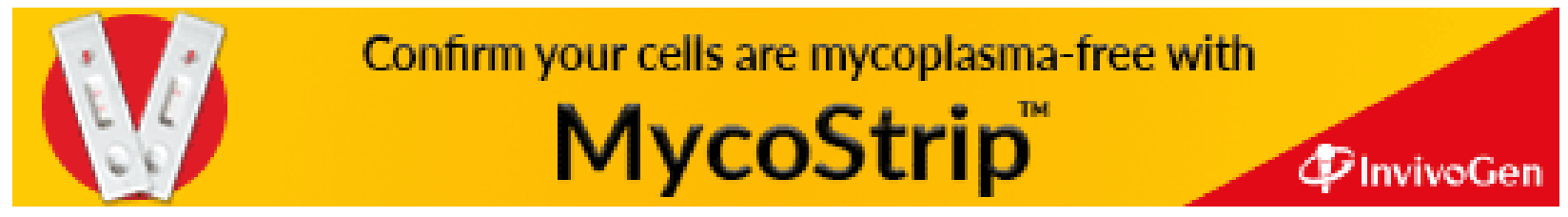

